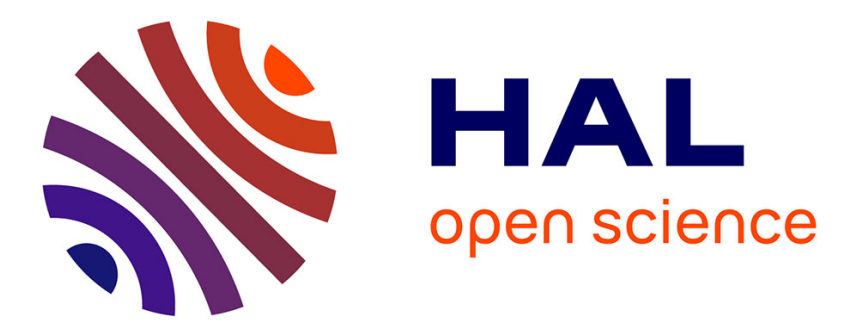

\title{
Use of functionalized nanosilica to improve thermo-mechanical properties of epoxy adhesive joint bonding aluminium substrates
}

C. Sperandio, A. Laachachi, D. Ruch, C. Poilâne, P. Bourson, Jean-Paul Salvestrini, S. Ahzi

\section{To cite this version:}

C. Sperandio, A. Laachachi, D. Ruch, C. Poilâne, P. Bourson, et al.. Use of functionalized nanosilica to improve thermo-mechanical properties of epoxy adhesive joint bonding aluminium substrates. Journal of Nanoscience and Nanotechnology, 2010, 10 (4), pp.2844-2849. 10.1166/jnn.2010.1458 . hal-00322143

\section{HAL Id: hal-00322143 \\ https://hal.science/hal-00322143}

Submitted on 2 Dec 2021

HAL is a multi-disciplinary open access archive for the deposit and dissemination of scientific research documents, whether they are published or not. The documents may come from teaching and research institutions in France or abroad, or from public or private research centers.
L'archive ouverte pluridisciplinaire HAL, est destinée au dépôt et à la diffusion de documents scientifiques de niveau recherche, publiés ou non, émanant des établissements d'enseignement et de recherche français ou étrangers, des laboratoires publics ou privés.

\section{다)(1) $(5$}

Distributed under a Creative Commons Attribution - NonCommercial| 4.0 International 


\title{
Use of Functionalized Nanosilica to Improve Thermo-Mechanical Properties of Epoxy Adhesive Joint Bonding Aluminium Substrates
}

\author{
C. Sperandio ${ }^{1,2}$, A. Laachachi ${ }^{1}$, D. Ruch ${ }^{1, *}$, C. Poilâne ${ }^{3}$, \\ P. Bourson ${ }^{2}$, J.-P. Salvestrini², and S. Ahzi ${ }^{4}$ \\ ${ }^{1}$ LTI-Centre de Recherche Public Henri Tudor-66 Rue de Luxembourg BP 144, \\ L-4002 Esch-sur-Alzette, Luxembourg \\ ${ }^{2}$ LMOPS, CNRS UMR 7132-Université Paul Verlaine Metz, Supélec, 2 Rue Edouard Belin 57070 Metz, France \\ ${ }^{3}$ LRPMN-Université de Caen-IUT d'Alençon-Pôle universitaire de Montfoulon, 61250 Damigny, France \\ ${ }^{4}$ IMFS (UMR 7507), University of Strasbourg, 2 Rue Boussingault, 67000 Strasbourg, France
}

\begin{abstract}
The present work is concerned with the improvement of thermal properties and mechanical strength of adhesive joints consisting of an epoxy adhesive layer bonding aluminium substrates by grafted nanosilica. Epoxy resin/silica nanocomposites were prepared by using functionalized silica. Silica was functionalized by amine group $\left(\mathrm{SiO}_{2}-\mathrm{NH}_{2}\right)$. It was identified by Raman and Fourier Transform Infrared (FTIR). Effects of silica on viscoelastic properties for epoxy resin and its assemblies with aluminium substrates were studied by Dynamical Mechanical Analysis (DMA). Particles distribution was characterized by Scanning Electron Microscope (SEM). Our experimental results showed that functionalized silica presents a better distribution in the matrix than the pure silica. Our results also showed that grafting of functionalized silica improves the glass transition temperature $(\mathrm{Tg})$ and the ultimate strength of aluminium/epoxy/aluminium assembly.
\end{abstract}

Keywords: Epoxy Adhesives, Assembly, Nanocomposite, Nanoparticles, Thermo-Mechanical Properties.

\section{INTRODUCTION}

The epoxy resin/metal assemblies are mainly used in paint and in glue because of their low cost and ease of use compared to other methods such as welding. ${ }^{1,2}$ It is well accepted that the properties of the interfacial region between two bonded materials have a significant influence on the behaviour and performance of the material system. Because of its low thermal stability, epoxy resin does not answer to high performance applications. It is therefore of interest to develop epoxy-based adhesives with high glass transition temperature. As known, thermal and mechanical properties of the epoxy resin can be improved by the incorporation of inorganic nanoparticles. Their higher surface area compared to microparticles can induce a better stress transfer which leads to an increase of ductility by nanocavitation and consequently of stiffness. ${ }^{3,4}$ Silica nanoparticles are commonly used for the reinforcement of the epoxy matrix to lower the shrinkage during curing, to decrease

\footnotetext{
*Author to whom correspondence should be addressed.
}

thermal expansion coefficients, to improve thermal conductivity, and to meet mechanical requirements. However, nanofillers tend to form aggregates during the synthesis of nanocomposites because of the high particle/particle interactions, due to high surface area, compared to particles/ polymer interactions. ${ }^{5}$ As a result, a good dispersion is necessary to obtain better final properties of the nanocomposite. One of the most promising solutions to improve the dispersion of nanofillers is the modification of the nanoparticle surfaces. ${ }^{6}$

In order to investigate the nanocomposite behaviour when the polymer contained pure or functionalized silica, epoxy-resin/silica-nanoparticles nanocomposites were jointed between two aluminium substrates. Many authors dealt with the impact of silica incorporation on the mechanical or thermal properties. ${ }^{7-10}$ However, few studies have focused on the assemblies shear behaviour. The aim of the present work is to study the effect of surface modification of nanosilica on thermo-mechanical properties of the bulk and its assemblies, especially dynamicmechanical behaviour. Stiffness is linked to viscoelastic 
stage, studied by DMA, and viscoplastic stage studied by tensile test.

\section{EXPERIMENTAL DETAILS}

\subsection{Materials}

The epoxy resin is a diglycidyl ether of bisphenol A (DGEBA), from Dow chemicals (DER331). The hardener is a diethylenetriamine (DETA), from Aldrich. Silica nanoparticles were produced by Aldrich (medium particle size of 15-20 nm and a specific surface area of $140-180 \mathrm{~m}^{2} / \mathrm{g}$ ). Aminopropyltriethoxysilane (APTES) (from Aldrich) was used to functionalize silica nanoparticle surfaces. Aluminum substrate was purchased from Goodfellow with a purity of $99.999 \%$.

\subsection{Surface Modification of Silica}

Silica nanoparticles were functionalized stoeichiometrically by linking the surface silanol groups with amine group. The surface modification is illustrated in Figure 1. $5 \mathrm{~g}$ of silica were dispersed by magnetic agitation into $60 \mathrm{ml}$ of APTES with $50 \mathrm{ml}$ of toluene during 4 hours. The resulting mixture was centrifuged, and the precipitate was washed several times with toluene and then dried in an oven at $150{ }^{\circ} \mathrm{C}$ under vacuum for 6 hours.

\subsection{Samples Preparation}

\subsubsection{Preparation of Nanocomposites}

All epoxy resin-silica nanocomposites were prepared by mixing, at $5 \mathrm{wt} \%$, the epoxy resin and silica or modified silica by magnetic agitation followed by ultrasonic dispersion during $15 \mathrm{~min}$. The aliphatic hardener, DETA, was added in a stoechiometric ratio to epoxy resin and stirred. Curing process applied was $1 \mathrm{~h}$ at $60{ }^{\circ} \mathrm{C}, 1 \mathrm{~h}$ at $100{ }^{\circ} \mathrm{C}$ and $2 \mathrm{~h}$ of post-curing at $120^{\circ} \mathrm{C}$.

\subsubsection{Preparation of Adhesive Assembly}

Epoxy resin and its nanocomposites were assembled between two substrates of aluminium in a simple recovery joint (Fig. 2). Aluminium (1024 series) with high purity of $99.999 \% \mathrm{Al}$, was degreased by acetone in an ultrasonic bath.

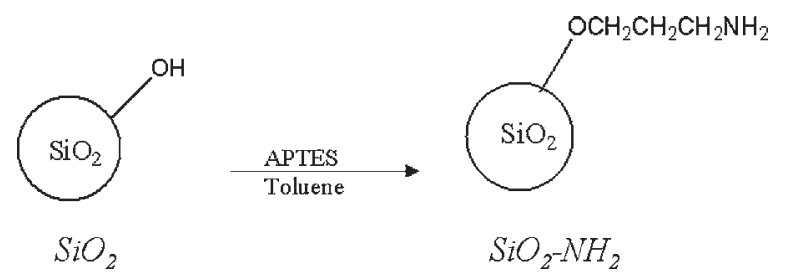

Fig. 1. Functionalization of nanosilica particles.

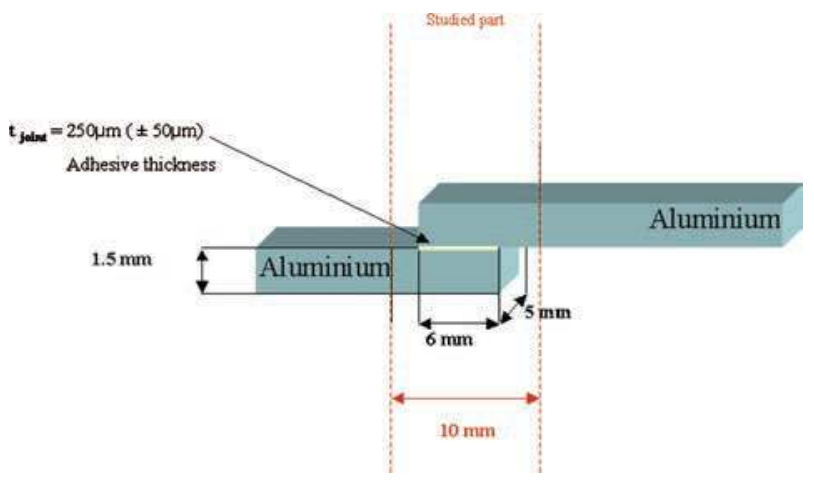

Fig. 2. Simple recovery joint aluminum assembly.

\subsection{Apparatuses}

To identify surface functional groups of modified silica, complementary spectroscopic methods were applied. Fourier Transform Infrared (FT-IR) measurements were performed on Brucker Tensor 27 with $4 \mathrm{~cm}^{-1}$ resolution and Raman measurements were carried out with JobinYvon Horiba $\left(0.3 \mathrm{~cm}^{-1}\right.$ of resolution). Thermogravimetric Analysis (TGA-Netzsch PC 409Luxx) was used to determine functionalization rate (FR) after functionalization of the silica nanoparticles. Measurement was carried out under nitrogen $\left(\mathrm{N}_{2}\right)$ with a heating rate of $5{ }^{\circ} \mathrm{C} / \mathrm{min}$ from 30 to $900{ }^{\circ} \mathrm{C}$. Scanning Electron Microscope (SEM, FEI Quanta 200) was used with an accelerating voltage of $7 \mathrm{KeV}$ and a pressure of $450 \mathrm{~Pa}$ to investigate particles size and dispersion inside the matrix. To examine the effect of silica incorporation on crosslinking, DSC (Netzsch DSC 200) was used. Accurately weighed samples of viscous mixture (before crosslinking) were cured in aluminium crucible from 25 to $200{ }^{\circ} \mathrm{C}$ at a heating rate of $10{ }^{\circ} \mathrm{C} / \mathrm{min}$ under $\mathrm{N}_{2}$ atmosphere, then cooled at $20^{\circ} \mathrm{C} / \mathrm{min}$. Elastic modulus $\left(E^{\prime}\right)$ and glass transition temperature $(T \mathrm{~g})$ of nanocomposites were determined by dynamic mechanical analyzer (Netzsch 242C) between 25 and $200{ }^{\circ} \mathrm{C}$ with a heating rate of $2{ }^{\circ} \mathrm{C} / \mathrm{min}$ and a frequency of $5 \mathrm{~Hz}$ then air quenched. Simple recovery joint was used for epoxy resin assemblies elaboration (Fig. 2). Mechanical properties of adhesive assemblies were investigated by DMA shear testing with the same parameters. Tensile tests were conducted in a servo-hydraulic testing machine (Instron), equipped with a $5 \mathrm{kN}$ load captor. All tests were performed at room temperature under displacement control mode at a crosshead speed of $0.5 \mathrm{~mm} / \mathrm{min}$.

\section{RESULTS AND DISCUSSION}

\subsection{Silica Modification}

FTIR and Raman were used to identify surface functional group of modified silica (Figs. 3 and 4 respectively). As shown in Figure 3, the main characteristic peaks of silica and modified silica were assigned as follows: 1064-1047, 


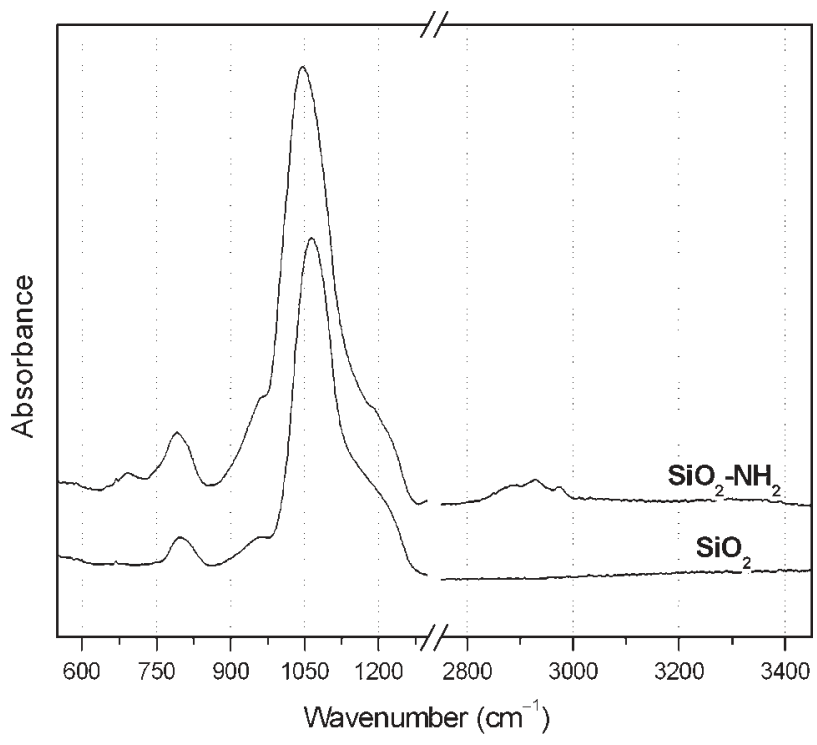

Fig. 3. FTIR spectrum for $\mathrm{SiO}_{2}$ and $\mathrm{SiO}_{2}-\mathrm{NH}_{2}$ nanoparticles.

963-960, and 798-792 $\mathrm{cm}^{-1}$ was attributable respectively, to $\nu(\mathrm{Si}-\mathrm{O}-\mathrm{Si}), \nu(\mathrm{Si}-\mathrm{OH})$ and $\delta(\mathrm{Si}-\mathrm{O}-\mathrm{Si})$. Moreover, the peak linked to $\nu(\mathrm{Si}-\mathrm{O}-\mathrm{Si})$ presents a shift called "bathochrome effect" between 1064 and $1047 \mathrm{~cm}^{-1}$ (shift of $18 \mathrm{~cm}^{-1}$ for $\mathrm{SiO}_{2}-\mathrm{NH}_{2}$ ). This shift is classically attributed to the structural change of silica after modification. In addition, Raman spectres confirm the presence of bands around $2875 \mathrm{~cm}^{-1}$ for $\mathrm{SiO}_{2}-\mathrm{NH}_{2}$ characteristics for $\mathrm{CH}_{2}$ group (Fig. 4). For $\mathrm{SiO}_{2}-\mathrm{NH}_{2}$ modified silica, it was observed the apparition of peak between 2930 and $2975 \mathrm{~cm}^{-1}$ attributed to N-H group (Fig. 3). This indicates that the amine is covalently bound to the surface of the silica particles.

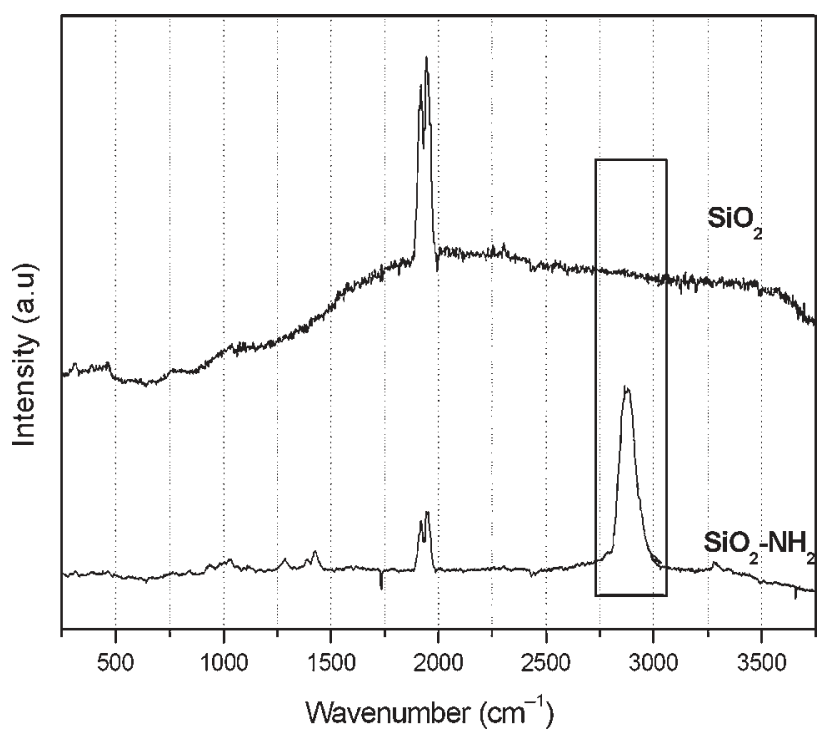

Fig. 4. Raman spectrum for $\mathrm{SiO}_{2}$ and $\mathrm{SiO}_{2}-\mathrm{NH}_{2}$ nanoparticles.

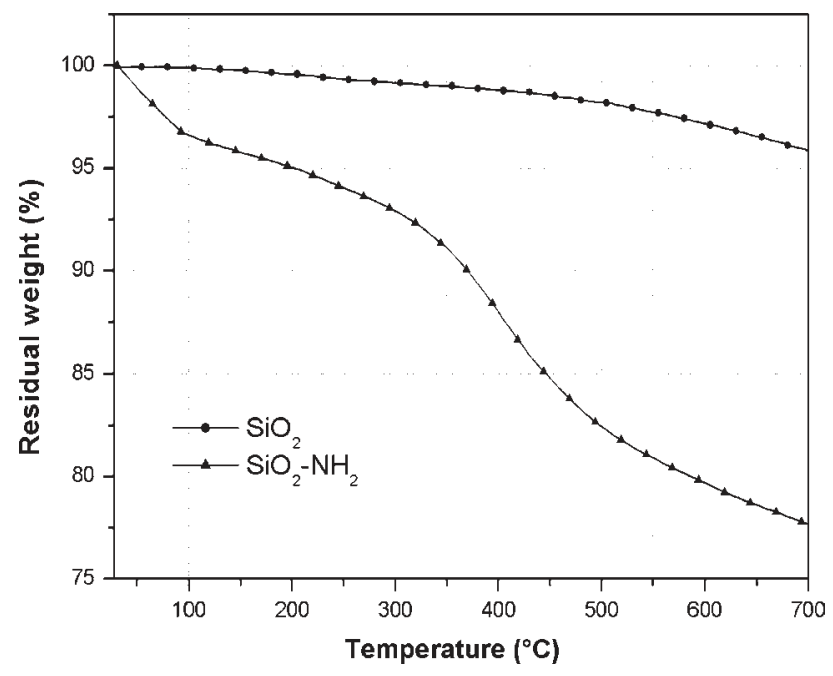

Fig. 5. Thermogravimetric curves for $\mathrm{SiO}_{2}$ and $\mathrm{SiO}_{2}-\mathrm{NH}_{2}$ nanoparticles.

In order to determine the amount and functionalization rate of modified silica, thermogravimetric was used. Figure 5 presents TGA curves for pure and modified silica. Weight loss was observed at $90{ }^{\circ} \mathrm{C}$ corresponding to a solvent evaporation and residual traces of water during and after synthesis. Second step of weight loss corresponds to the degradation of amines $\left(440{ }^{\circ} \mathrm{C}\right)$. The functionalization rate was calculated directly from the second weight loss step $\left(21 \%\right.$ for $\left.\mathrm{SiO}_{2}-\mathrm{NH}_{2}\right)$. By using a simple calculation, molar percentage of amine group presents onto the surface of silica respectively corresponds to $0.00796 \% \mathrm{~mol} \cdot \mathrm{mg}^{-1}$.

\subsection{Morphology of Nanocomposites}

The SEM analysis of the nanocomposites (epoxy resin loaded with $5 \mathrm{wt} \%$ of silica and modified silica) was carried out in order to investigate the dispersion and distribution of silica nanoparticles in the matrix. Figure 6 shows typical micrographs obtained. It can be observed that $\mathrm{SiO}_{2}-\mathrm{NH}_{2}$ modified silica presents a better dispersion with a little tendency to aggregation compared to pure silica.

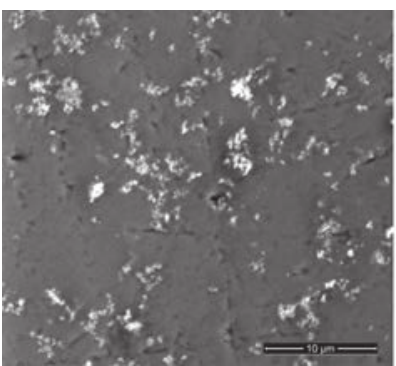

$\mathrm{ER}+5 \% \mathrm{SiO}_{2}$

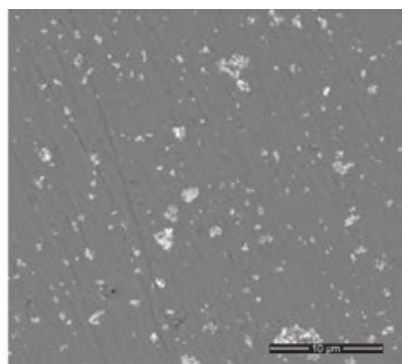

$\mathrm{ER}+5 \% \mathrm{SiO}_{2}-\mathrm{NH}_{2}$
Fig. 6. SEM micrographs of epoxy/silica nanocomposites filled at $5 \mathrm{wt} \%$ of pure $\mathrm{SiO}_{2}$ and $\mathrm{SiO}_{2}-\mathrm{NH}_{2}$. 


\subsection{Effect of Silica on the Crosslinking Rate}

The thermal and mechanical properties of epoxy resins are highly dependent on the crosslinked three-dimensional microstructure formed during the curing process. The crosslinking was studied by dynamic DSC. Figure 7 shows the thermograms curves corresponding to the dynamic curing of epoxy resin/hardener in presence of silica and modified silica at $10{ }^{\circ} \mathrm{C} / \mathrm{min}$. For all formulations, only an exothermal peak is observed in the curing, which could correspond to the polymerization between DGEBA and DETA. As can be seen, the temperature of the maximum of the crosslinking exothermic reaction is constant for all formulations. However, the enthalpy increases in presence of silica and modified silica (respectively, 470 for ER, 483 for $\mathrm{SiO}_{2}$, and $485 \mathrm{~J} / \mathrm{g}$ for $\mathrm{SiO}_{2}-\mathrm{NH}_{2}$ ). This could be attributed to a catalytic role of oxide in curing process. The silica can be also susceptible to change significantly the heat transfer for the epoxy resin system during curing process. A contradictory result to ours was obtained previously by Rosso et al. ${ }^{11}$ which shows a decrease of the curing enthalpy with the amount of silica in the epoxy resin matrix. To explain this decrease, the formation of an amino-rich region around the silica nanoparticles was proposed. Moreover a lower content of hardener inhibits the completion of epoxy group reactions.

\subsection{Effect of Silica on Mechanical Properties of Nanocomposites}

The dynamic mechanical properties of the crosslinked materials were obtained as a function of the temperature start from the glassy state to the rubbery plateau of each material. Figure 8 shows the elastic modulus $E^{\prime}$ and $\tan \delta$ of some representative samples of epoxy resin and its

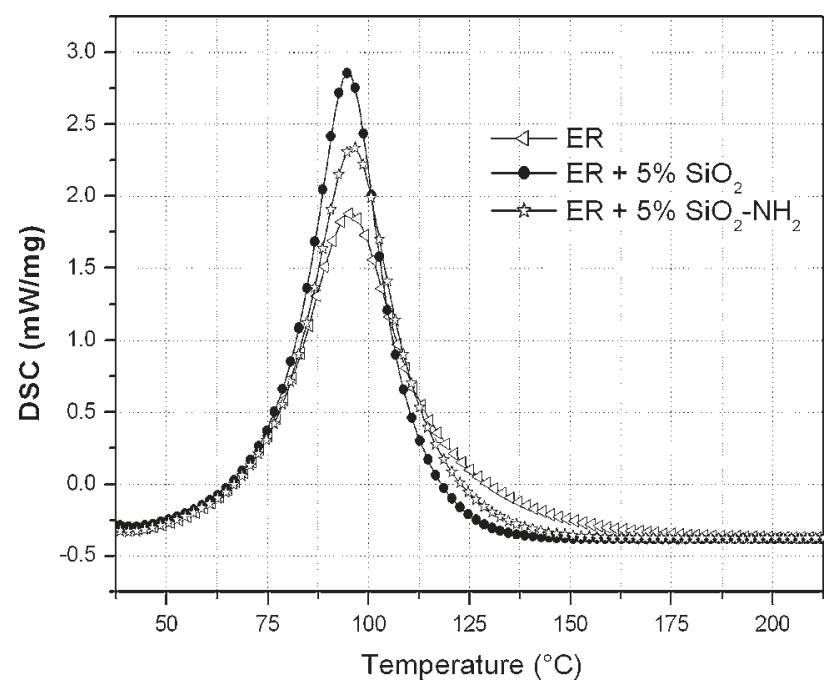

Fig. 7. Crosslinking rate curves of pure epoxy resin and its nanocomposites containing pure $\mathrm{SiO}_{2}$ and $\mathrm{SiO}_{2}-\mathrm{NH}_{2}$.

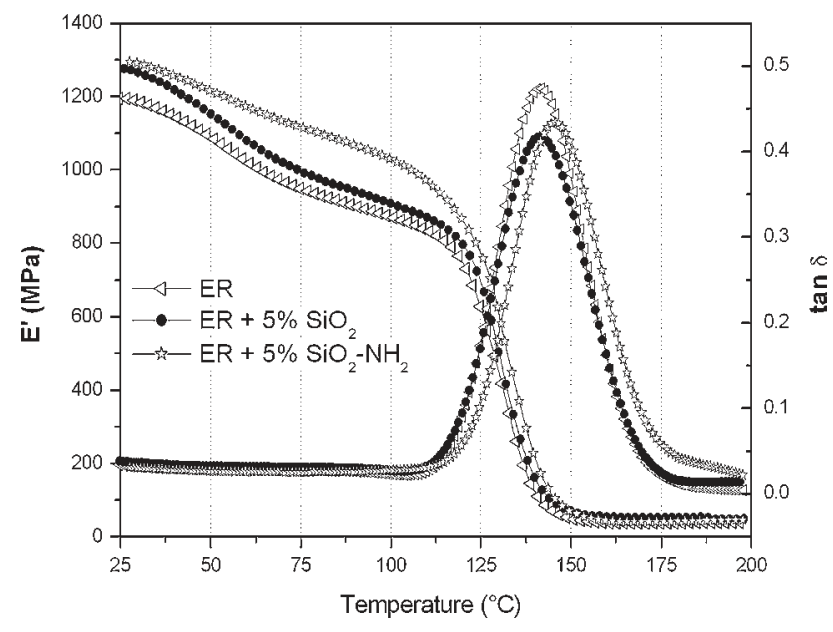

Fig. 8. DMA single cantilever results of pure epoxy resin and its nanocomposites containing pure $\mathrm{SiO}_{2}$ and $\mathrm{SiO}_{2}-\mathrm{NH}_{2}$.

nanocomposites with silica and modified silica. The initial elastic modulus of the materials with silica and modified silica was higher than the pure material (by about $100 \mathrm{MPa}$ ), and the modulus tends to zero after the glass transition for all materials with or without silica. $T \mathrm{~g}$ of epoxy resin and its nanocomposites are indicated by the peak of $\tan \delta$ shown in Figure 8. In several cases, the dispersion, the particle size and surface modification of the particles play important roles in the changes in $T \mathrm{~g} .{ }^{12,13}$ In our systems, $\tan \delta$ shows that the incorporation of pure nanosilica did not have a significant effect on $T \mathrm{~g}$ of the nanocomposite $\left(\mathrm{Tg}\right.$ is the same for $\mathrm{ER}$ and $\mathrm{ER}-5 \% \mathrm{SiO}_{2}$ which is about $141{ }^{\circ} \mathrm{C}$ ). However, grafting of functionalized nanosilica have a significant impact. The $T \mathrm{~g}$ increases by $4{ }^{\circ} \mathrm{C}$ for the nanocomposite with $\mathrm{SiO}_{2}-\mathrm{NH}_{2}$. This change of glass transition is probably due to the variation of polymer chain mobility. A restriction of polymer chain mobility often induces an increase of the $T \mathrm{~g}$. On the other hand, a lower $T \mathrm{~g}$ allows for greater polymer chain mobility. According to Crawford and Lesser, ${ }^{14}$ the glass transition temperature of polymer is dependent on three factors: crosslink functionality, molecular weight between crosslinks, and chain stiffness. In our case, it was shown that the modification of the crosslinking rate (Fig. 6) doesn't explain the increase in $T \mathrm{~g}$ observed with grafted nanosilica. ${ }^{15}$ Sangermano et al. ${ }^{16}$ have observed a slight increase of $T \mathrm{~g}$ for a resin filled with $10 \mathrm{wt} \%$ of silica. They have attributed this increase to a chain transfer mechanism involving $\mathrm{OH}$ groups from silica surface. In the presence of nanofillers, the increasing of $T \mathrm{~g}$ is the consequence of a good dispersion and a strong filler/polymer adhesion.

\subsection{Effect of Silica on Mechanical Properties of Assemblies}

The dynamic mechanical properties of the assemblies (Fig. 2) with and without nanosilica were obtained as a 


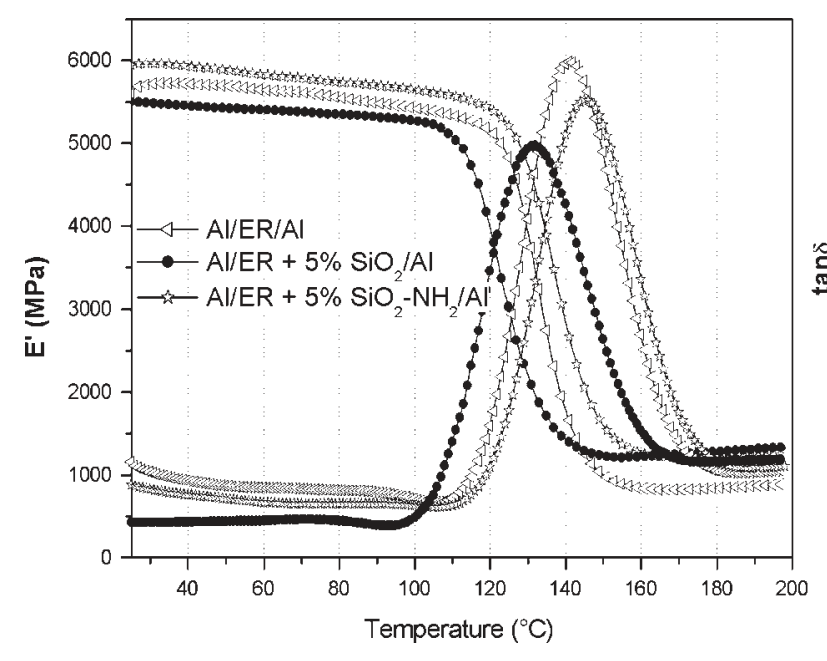

Fig. 9. DMA shear tests results of pure epoxy resin assembly and its nanocomposites containing pure $\mathrm{SiO}_{2}$ and $\mathrm{SiO}_{2}-\mathrm{NH}_{2}$.

function of the temperature from below the glassy state to the rubbery plateau of each assembly. Figure 9 shows the elastic modulus $E^{\prime}$ and $\tan \delta$ of some representative samples of $\mathrm{Al} / \mathrm{ER} / \mathrm{Al}$ and assemblies with silica and modified silica. The elastic modulus $E^{\prime}$ for epoxy assembly is higher (5720 MPa) than epoxy crosslinked without aluminium substrates (bulk epoxy, $1200 \mathrm{MPa}$ ). Grafting of modified nanosilica show a slight improvement in module $E^{\prime}(6000 \mathrm{MPa})$ compared with unfilled assembly. However, the incorporation of pure nanosilica induces a slightly decrease of $E^{\prime}(5500 \mathrm{MPa})$. As known, glassy modulus of polymers is relatively independent on chain stiffness. For epoxy assembly (Al/ER/Al), $\tan \delta$ shows that no change in the $T \mathrm{~g}\left(141^{\circ} \mathrm{C}\right)$ compared to bulk epoxy resin. Bentadjine et al. ${ }^{17}$ reported that there was a difference of $T \mathrm{~g}$ between the interphase and the bulk in an epoxy/aluminium system. The incorporation of nanosilica in the matrix affects the glass transition by $9^{\circ} \mathrm{C}$ which is attributed to a plasticizing effect of silica aggregate. However, when the graft of modified silica was used the $T \mathrm{~g}$ of the assembly increases by $5{ }^{\circ} \mathrm{C}$ for $\mathrm{SiO}_{2}-\mathrm{NH}_{2}$. It has been shown by $\mathrm{SEM}$ that the grafting of nanosilica improves the dispersion compared to the physical incorporation in the matrix. As a consequence, the reason why this property increases in the presence of the nanoparticles can be discussed on the basis of the restriction of the mobility of the polymer chains resulting from: (i) particle/polymer compatibility due to bond creation by functionalized particle compared to weak interaction between the oxide surface of the pure silica and polymer, (ii) the steric hindrance due to the presence of rigid particles, and (iii) the good dispersion.

\subsection{Effect of Silica on Mechanical Strength of Assemblies}

Five samples of each system were tested for measuring the mechanical stiffness properties of neat assembly and

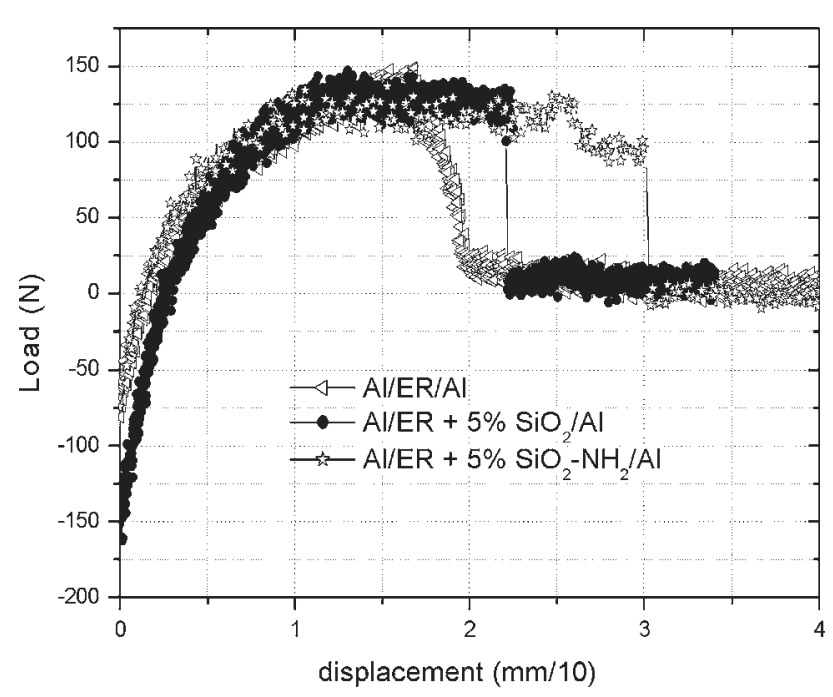

Fig. 10. Typical load-displacement curves for pure epoxy resin assembly and its nanocomposites containing pure $\mathrm{SiO}_{2}$ and $\mathrm{SiO}_{2}-\mathrm{NH}_{2}$.

assembly with silica samples. Ultimate strength of the assemblies was defined as a value of the sample failure (elongation at break). Figure 10 shows the representative load-displacement curves during the tensile test. The negative load at the beginning of tensile test is due to the formal stress of sample. The crack propagation occurred entirely in a controlled manner during the entire measurement period for each system. No abrupt fracture took place once the crack started to propagate. Ultimate strength was remarkably improved by the presence of nanosilica. However, incorporation of pure nanosilica does not have significant impact on mechanical strength (ultimate strength increased by $23 \%$ ) compared to functionalized silica, which show the highest displacement and maximum area under the load-displacement curve. Assembly with $\mathrm{SiO}_{2}-\mathrm{NH}_{2}$ presents an increase of the ultimate strength of $66 \%$ compared to assembly without silica. It is also clear that, in the present case, covalent bonds between epoxy and functionalized silica nanoparticles play an important role in mechanical properties of the adhesive assemblies. These results confirm that the degree of nanoparticles distribution is able to improve the stiffness and the ultimate strength of the epoxy resin.

\subsection{Correlation Between Particles Incorporation and Mechanical Properties}

It is very beneficial to study the correlation between nanoparticles functionalization and the corresponding property improvement of the nanocomposites. Due to surface modification, strong interactions between nanoparticles and polymer chains are expected. These changes undergo specific tight bindings so that the hydrodynamic radius of the particles is affected. This is usually called core-shell building block. ${ }^{18}$ Zhang et al. ${ }^{9}$ have studied the effect of core-shell formation on mechanicals properties 
of epoxy resin nanocomposite. ${ }^{9}$ In the presence of nanosilica, the authors showed significant improvements for both stiffness and toughness when the interparticle distance was smaller than the nanoparticle diameter. Under this condition, the interphase particle/polymer may construct a threedimensional physical network, which will dominate the performances of these nanocomposites. Combined with the latter observation, another approach can be taken in consideration according to many studies; the performance of adhesive bonds depends strongly on the properties of an interphase region between the adhesive polymer and the substrate and would have different properties from those of the bulk adhesive. ${ }^{6,19,20}$ This interphase is created by amine modifications by chemisorption and basically dissolution of substrate oxide and/or hydroxide. ${ }^{21}$ Montois et al. ${ }^{22}$ have studied the effect of the epoxy resin viscosity on the interphase formation and its thickness. They observed that the increase of the resin viscosity affect the interphase thickness. Sanctuary et al. ${ }^{23}$ studied epoxy resin filled with alumina and silica nanoparticles. They observed that the size of the nanoparticles and their concentration should influence the average mobility of the DGEBA molecules and increase the bulk viscosity.

According to these points, grafted silica nanoparticles onto epoxy resin lead to create a strong interaction epoxy resin/nanoparticle, this increase the bulk viscosity and can create a 3D network.

\section{CONCLUSION}

The effect of functionalized nanosilica on the thermomechanical properties of epoxy resin bulk and of Aluminium/Epoxy/Aluminium assembly was investigated by DMA. Concerning the particles distribution, it was shown that the functionalized nanosilica is well distributed in the material but with some little tendency to aggregation. Functionalized nanosilica increase the glass transition temperature of epoxy adhesive which was attributed to a restriction of polymer chain mobility and to a good nanoparticles distribution. The study of the interphase formation between adhesive and aluminium substrate and its influence on mechanical strength are in progress.

\section{References and Notes}

1. W. G. Potetr, Epoxide Resins, Springer, New York (1970).

2. B. Ellis, Chemistry and Technology of Epoxy Resins, Blackie Academic and Professional Ed (1993).

3. B. Abramoff and J. Convivo, J. Appl. Polym. Sci. 46, 1785 (1992).

4. Y. Nakamura, M. Yamaguchi, and M. Okubo, J. Appl. Polym. Sci. 45, 1281 (1992).

5. J. Karger-Kocsis, Z. Zhang, J. F. Calleja, and G. Michler, CRC Press, New York (2005), p. 547.

6. E. P. Plueddemann, Plenum Press, New York (1982).

7. L. E. Nielsen and R. F. Landel, Handbook of Mechanical Properties of Polymers and Composites, edited by M. Deckker, New York (1994), p. 377.

8. S. Kang, S. I. Hong, C. R. Choe, M. Park, S. Rim, and J. Kim, Polym. 42, 879 (2001).

9. H. Zhang Z. Zhang, K. Friedrich, and C. Eger, Acta. Mater. 54, 1833 (2006).

10. Y. Zheng, Y. Zheng, and R. Ning, Mater. Lett. 57, 2940 (2003).

11. P. Rosso and L. Ye, Macromol. Rapid Commun. 28, 121 (2007).

12. B. J. Ash, L. S. Schadler, and R. W. Siegel, Mater. Lett. 55, 83 (2002)

13. M. Xiong, G. Cu, B. You, and L. Wu, J. Appl. Polym. Sci. 90, 1923 (2003).

14. E. Crawford and A. J. Lesser, J. Polym. Sci. Part B: Polym. Phys. 36, 1371 (1998).

15. Y. Sun, Z. Zhang, K. Moon, and C. P. Wong, J. Appl. Polym. Sci.: Part B: Polym.Phys. 42, 38 (2004).

16. M. Sangermano, G. Malucelli, and E. Amerio, Prog. Org. Coat. 54, 134 (2005).

17. S. Bentadjine, R. Petiaud, A. A. Roche, and V. Massardier, Polym. 42, 6271 (2001).

18. G.-M. Odegard, T.-C. Clancy, and T.-S. Gates, Polym. 46, 553 (2005).

19. C. Fauquet, P. Dubot, and L. Minel, Appl. Surf. Sci. 81, 435 (1994).

20. S. Bentadjine, A. A. Roche, J. Bouchet, Adhesion Aspects of Thin Films, edited by K. L. Mittal (2001), p. 239.

21. A. A. Roche, Int. J. Adhes. Adhes. 22, 431 (2002).

22. P. Montois, V. Nassiet, J.-A. Petit, and D. Adrian, Int. J. Adhes. Adhes. 27, 145 (2007)

23. R. Sanctuary, J. Baller, J. K. Kruger, D. Schaefer, and R. Bactavatchalou, Thermochim. Acta 445, 111 (2006). 